Retraction

\title{
Retracted: Power Consumption, Mixing Time, and Oxygen Mass Transfer in a Gas-Liquid Contactor Stirred with a Dual Impeller for Different Spacing
}

\author{
Journal of Engineering \\ Received 9 April 2017; Accepted 9 April 2017; Published 11 May 2017 \\ Copyright (c) 2017 Journal of Engineering. This is an open access article distributed under the Creative Commons Attribution \\ License, which permits unrestricted use, distribution, and reproduction in any medium, provided the original work is properly \\ cited.
}

At the request of the author, the article titled "Power Consumption, Mixing Time, and Oxygen Mass Transfer in a Gas-Liquid Contactor Stirred with a Dual Impeller for Different Spacing" [1] has been retracted. The data presented in the article were published without the permission of the University of Toulouse.

\section{References}

[1] H. M. Issa, "Power consumption, mixing time, and oxygen mass transfer in a gas-liquid contactor stirred with a dual impeller for different spacing," Journal of Engineering, vol. 2016, Article ID 3954305, 7 pages, 2016. 


\title{
Power Consumption, Mixing Time, and Oxygen
} Mass Transfer in a Gas-Liquid Contactor Stirred with a Dual Impeller for Different Spacing

\author{
Hayder Mohammed Issa \\ College of Engineering, Salahaddin University-Erbil, Erbil, Iraq \\ Correspondence should be addressed to Hayder Mohammed Issa; hayder.issa@su.edu.krd
}

Received 25 November 2015; Revised 23 January 2016; Accepted 27 January 2016

Academic Editor: Tingyue Gu

Copyright (C) 2016 Hayder Mohammed Issa. This is an open access article distributed under the Creative Commons Attribution License, which permits unrestricted use, distribution, and reproduction in any medium, provided the original work is properly cited.

\begin{abstract}
Multiple or dual impellers are widely implemented in stirred contactors used in various biological processes like fermentation, water treatment, and pharmaceutical production. The spacing between impellers is considered as a crucial factor in designing of these types of contactors resulting in variation of oxygen mass transfer, mixing time, or power consumption for such biological system. A study of three parts was conducted to characterize the effect of the spacing between impellers on the most important parameters that related to biological contactor performance: oxygen mass transfer coefficient $k_{l} a$ from the gas phase (air) to the liquid phase (water), mixing time, and power consumption for different operating rotational speeds (1.67-3.33 rps) and for three different spacing positions. The used impellers system in the study is a dual impeller system which consists of an inverted and bladed rotated cone (IBRC) and a pitched-blade up-flow propeller (PBPU). The experimental results showed that the shorter spacing (the lower PBPU in a higher position) is more convenient, as the achieved oxygen mass transfer coefficient has showed an improvement in its values with lower mixing time and with a slight alteration in power consumption.
\end{abstract}

\section{Introduction}

Gas-liquid contacting is considered as one of the most important operations in chemical process industries, with or without solid existence [1]. The gas-liquid dispersion and homogenization in stirred tanks are involved within many industrial processes like fine chemicals manufacturing and biochemical fermentation, whereas the gas-liquid phases in stirred or agitated vessels are widely implemented in various processes of the chemical, mining, pharmaceutical, and biotechnological industries [2,3]. Agitation or mixing might be a crucial factor in the chemical, biotechnological, pharmaceutical, and food processing; hence the mixing in stirred tanks is used to increase heat and mass transfer rates, to prevent particle settling, to obtain emulsions, and to even out all physical property gradients [4]. Gas-liquid processes, in particular, like fermentation and a variety of oxygenation (aeration) and hydrogenation processes, need a large gas handling capacity and effective gas dispersion for generating as large interfacial area as possible [5].

Multiple impeller systems are used in various industrial applications, namely, fermentation, gas-liquid reactions such as hydrogenation, dissolution, and crystallization, polymerization reactors, wastewater treatment, and so forth [6]. Multiple or dual impellers are preferred over a single impeller as multiple impellers provide better gas utilization in gas-liquid system due to the higher gas phase residence time, narrower spread in the residence time distribution in the flow systems, and higher surface area per unit liquid volume for heat transfer [6]. Different multiple impellers are used for aeration. For gas dispersion, usually combinations of DT (Rushton) radial impellers were used. The poor top-to-bottom liquid mixing condition with reduced mass transfer potential created by this system drew attention toward multiple impellers with downor up-pumping impellers to improve liquid blending and gas dispersion together and to increase mass transfer potential 
[7]. The flow pattern in multiple impellers stirred tank is remarkably altered compared to when that one impeller was used due to the interactions in circulation loops generated by impellers; this interaction in turn is affected greatly by impeller spacing [8]. For wastewater treatment, many other impeller combinations are used like turbine and propeller system [9] instead of using a single rotating cone as illustrated by Adachi [10] for the same purpose.

Hudcova et al. [11] have found that, for aerated conditions, the equations that were used for power consumption for a single Rushton turbine impeller could be extended relatively and easily to dual impellers. The power draw for each radial or axial impeller relies on its geometry and/or the tank geometry (for radial impellers) as found by Chapple et al. [12]. Usually in the aerated condition the power consumption is relatively decreased compared with the nonaerated condition. This reduction varies depending on the type of impeller and impellers combination $[13,14]$. The influence of spacing between two impellers on power consumption might possibly be limited with the existence of tank baffles [15]. The mutual interaction between two radial impellers' (Rushton turbines) performances was noticed through the great power dependence on the spacing between them as higher power number was recorded with longer spacing [15]. This phenomenon was remarked also for non-Newtonian fluids by Broniarz-Press et al. [16].

The mixing time in the aerated condition is slightly changed from the unaerated condition for both up- and down-pumping impellers combination [17]. Mahmoudi and Yianneskis [18] have observed three different flow patterns and mixing times with different impeller spacing. They found that, for long spacing between the impellers, the mixing times were nearly the longest and about $40 \%$ higher than for small spacing. This influence exists for all types of impeller configurations as the spacing affects significantly the produced flow field inside tanks $[19,20]$. For unaerated condition, the same dependence of mixing time on the impeller, spacing has been noticed by Magelli et al. [21]. The type of impeller is the key parameter to determine the quality of this dependence. There is a variation in the relation with the spacing according to impeller type from Rushton turbine to hydrofoil type [22].

Even though many studies have found that multiple impeller configurations are more efficient at achieving higher oxygen mass transfer in aerated systems due to the reduction in mixing time $[23,24]$ no one has investigated the effect of spacing between these impellers on the oxygen transfer. Impellers combinations at the same conditions of power draw and gas flow rate have little impact on volumetric oxygen mass transfer coefficient according to Gabelle et al. [25]. While Xie et al. [26] have reached the same results but for a specific range (higher flow rate) for gas flow rate and equal power input, Moucha et al. [27] have reached the opinion that impeller configurations with higher power number can reach the desired $k_{l} a$ at lower impeller speed.

The aim of this study is to characterize and interpret the spacing impact between the used up-pumping impellers (inverted bladed rotating cone (IBRC) + 4-pitched-blade upflow propeller (PBPU)) in a surface aerated stirred tank experimentally. Three experimental sets were conducted

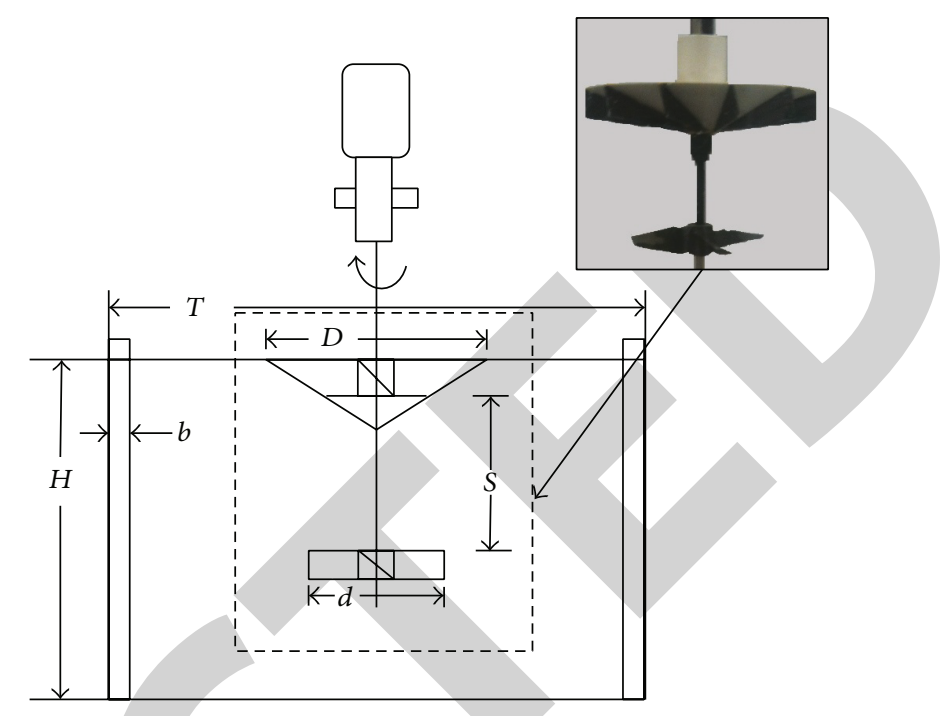

FIGURE 1: The schematic diagram of the experimental setup with presenting the picture of used impellers.

for power consumption, mixing time, and oxygen transfer coefficient in relation to impellers spacing and the obtained experimental results are essentially discussed.

\section{Experimental and Calculations}

The experimental runs were carried out in a cylindrical flat bottom gas-liquid contactor vessel with inside diameter of $0.8 \mathrm{~m}$. The vessel was made of transparent fibreglass. The schematic diagram of the system is shown in Figure 1. Three baffles of width, $b(0.1 T)$, were used with the experimentation to prevent or lessen the tangential circulatory flow that was created by the system (the baffles have the same height of the vessel seen in Figure 1).

In this work an impeller combination (IBRC + PBPU) is employed: an inverted and bladed rotated cone (IBRC) and a pitched-blade up-flow propeller (PBPU). Impellers (IBRC + PBPU) are used for mixing and gas-liquid contact purposes (aeration in this study) with the up-pumping operation. The IBRC was placed at the water surface. In all the cases an acceptable mixing has been provided to obtain a good contact interfacial area between the contents. The function of the lower four blades (PBPU) is redirecting the liquid flow toward the upper rotating cone (IBRC) for ensuring continuous feeding intake of the rotating cone. The other important function of the propeller is the contribution to achieve the well-mixing and distribution of the vessel. The geometrical ratio for the propeller $(d / T)=0.15$, which is lower than the general applied ratio $(d / T)$ for axial flow impellers $(0.2-0.7)$. Propeller blades have a width of $0.018 \mathrm{~m}$ and were placed on the propeller hub ring with a pitched angle of $45^{\circ}$. In this study, the role of the mixing is supporting the surface aeration process. The surface aeration is achieved by water droplets impingement and eddies generation at the water surface renewal due to the rotation of the inverted cone. The number of blades of the rotating cone is 12 (blades width 
and height are $0.24 \mathrm{~m}$ and $0.3 \mathrm{~m}$, resp.), with diameter ratio $D / T=0.24$. Water height was kept constant at $(0.38 T)$.

2.1. Power Consumption Measurement. The consumed power by the system was calculated by the torque measurement; the actual consumed power was calculated by applying the following equation:

$$
P=2 \pi N\left(T_{o}-T_{o e}\right),
$$

where $T_{o}$ and $T_{o e}$ are the measured torques in filled and empty vessel, respectively, in $\mathrm{N} \cdot \mathrm{m}$. A torque meter was used with torque capture transducer. The dimensionless power number was determined by the following:

$$
N_{p}=\frac{P}{\rho N^{3} D^{5}} .
$$

2.2. Mixing Time $\left(t_{95}\right)$. Mixing time $\left(t_{95}\right)$ is the time required to achieve the desired or specified degree of homogeneity. The desired degree of mixing used is normally fixed at $95 \%$, which means that the mixing time is the time when tracer concentration reaches or remains constant within $5 \%$ range of the final concentration [28]. Mixing time experiments were performed for the aerated tank for the tested spacing configurations in order to determine the mixing performance of each spacing configuration and interpret its influence on the mixing time. The injection position was kept for the same position at the water surface for all tests to eliminate the effect of injection variation on the results obtained.

The mixing time was determined by applying the colorization-decolorization method. It consists of coloring the water with iodine solution and then in decolorizing it with sodium thiosulfate solution. The decolorization reaction occurs progressively from yellowish brown color to clear water.

2.3. Mass Transfer Experimental Setup and Calculations. For the used experimental materials water and air, a probe was employed to measure the dissolved oxygen concentration. The measurements were achieved in depending on the oxygen partial pressure with correction for the affecting factors such as the temperature. The concentration units are expressed in milligrams of oxygen per liter of water $\left(\mathrm{mg} / \mathrm{dm}^{3}\right)$. The average percentage error of probes readings was calculated by least squares best fit between experimental and theoretical readings. Average percentages error was $\pm 3.49 \%$.

The mass transfer during the aeration process occurred mostly from the water surface to inside the liquid body. The theory of oxygen mass transfer coefficient calculation depends on the two-film theory, where all resistances to the oxygen mass transfer occur only in the liquid film and phase, while this resistance is ignored in the gas film. So the oxygen mass transfer coefficient in the gas phase is neglected. It was assumed that no other mass transfer occurs during the operation for the other constituents from the air toward the water and also for the used nitrogen gas during the deoxygenating process.
The calculation of the oxygen mass transfer, $k_{l} a$, was based on several general assumptions: the fluid in the vessel is evenly mixed; subsequently the $k_{l} a$ values throughout the vessel can be represented as one value. Also, the saturated dissolved oxygen could be represented as one value. The other mass transfer that is related to other constituents from the air toward the water as well as the nitrogen gas during the deoxygenating process is neglected. A weak heat gradient occurs during the aeration; in that manner the accompanied heat transfer was ignored.

The response time for the used probe was determined by depending upon both the experimental and theoretical results of dissolved oxygen. The theoretical values of the dissolved oxygen were determined by $[29,30]$

$$
C_{t}=C_{s}-\left(C_{s}-C_{o}\right) e^{-t / \tau}
$$

$\tau$, response time, was determined for the DO probe which was $8.8 \mathrm{sec}$.

The relationship between the DO and time with taking into account the effect of probe response time could be represented as the following equation [31-33]:

$$
\frac{d C_{l}}{d t}=k_{l} a\left(C_{s}-C_{l}\right) \text {. }
$$

By rearranging,

$$
\ln \frac{\left(C_{s}-C_{t}\right)}{\left(C_{s}-C_{o}\right)}=k_{l} a \cdot t
$$

The effect of probe response time on the DO concentration measurement for aeration processes was determined by the following equation [34]:

$$
C_{t}=C_{s}+\frac{C_{s}-C_{t}}{C_{s}-C_{o}}\left(k_{l} a \cdot \tau e^{-t / \tau}-e^{-k_{l} a t}\right) .
$$

The oxygen mass transfer relation with time for different spacing with considering the probe response time was implied in the applied mass transfer equation that represents the experimental runs to take into account the experimental errors. It is needed to correct the measured oxygen transfer coefficient in the liquid to the standard conditions, where the following equation is applied [35]:

$$
\left(k_{l} a\right)_{20^{\circ} \mathrm{C}}=1.024^{(20-\theta)}\left(k_{l} a\right)_{\theta} .
$$

\section{Results and Discussion}

The implemented calculation for the oxygen mass transfer, $k_{l} a$, in the experimentation was based on water deoxygenated by bubbling the nitrogen gas through the water inside the vessel till the lowest level could be achieved $(\leq 0.5 \mathrm{mg} / \mathrm{L})$. The operating fluid during all experimental runs was water.

The measurement of the dissolved oxygen deficit was carried out by an optical probe, which was placed inside the tank, as the liquid is well mixed, and the variation in $k_{l} a$ measured values was very limited. Seven different positions for the oxygen probe were tested and they gave 


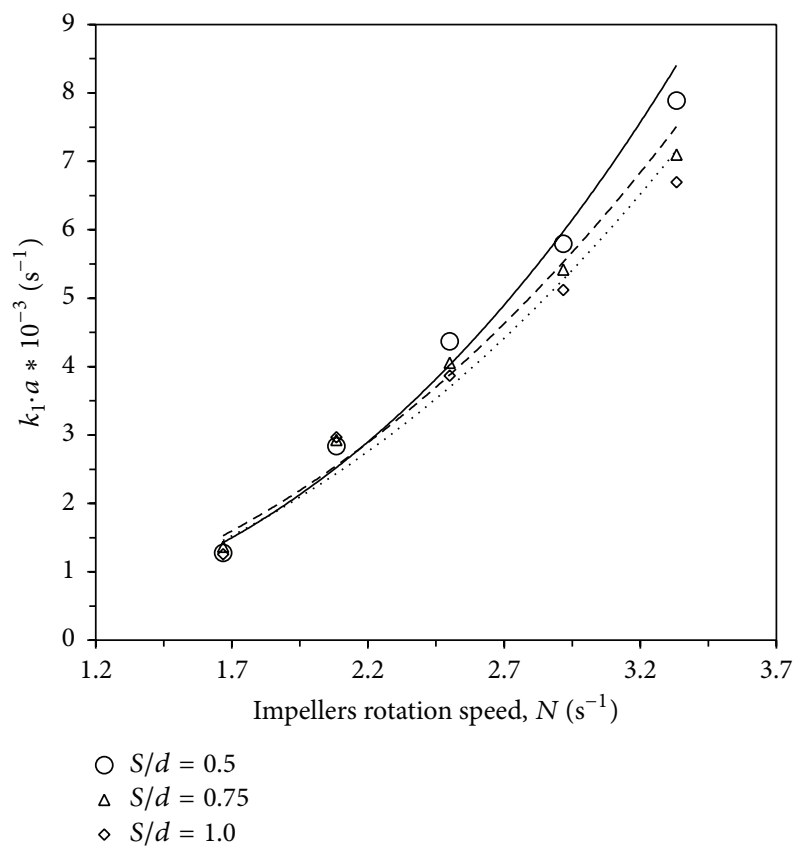

FIGURE 2: Spacing effect on the oxygen mass transfer coefficient.

close readings for the dissolved oxygen concentration with very little difference. This difference is caused by the simple accumulation of oxygen fine bubbles on the probes despite the effective circulation that occurs in the vessel.

\subsection{Effect of Spacing between Impellers on Oxygen Mass Trans-} fer. The lower PBPU in up-flow operation was added to assist the upper turbine (rotated cone) IBRC aeration performance by redirecting the flow toward the upper impeller intake in order to eliminate any feed shortage and to achieve the homogenous distribution of dissolved oxygen in the entire tank. This aim was reached by ensuring the flow circulation through all tank parts especially the deep levels. The presence of short circulations that might occur in the upper half of the tank was eliminated by forcing the flow to continue its circulation down to the tank deep bottom.

From Figure 2, the relationship between oxygen mass transfer coefficient $k_{l} a$ and impellers speed for three spacing levels between $(S / d=0.5,0.75,1)$ is presented. Where at lower speed $1.67 \mathrm{rps}$ the lowest $k_{l} a$ was achieved, it is about $1.3 \times 10^{-3} \mathrm{~s}^{-1}$ for the three tested spacing ratios. At the speed of $2.5 \mathrm{rps}$, higher $k_{l} a$ was accomplished of $(5.42-5.8) \times 10^{-3} \mathrm{~s}^{-1}$ for spacing ratios $S / d 0.75$ and 1, respectively. When impeller speed reaches its higher level of $3.33 \mathrm{rps}, k_{l} a$ is increased to $7.1 \times 10^{-3} \mathrm{~s}^{-1}$ and $7.89 \times 10^{-3} \mathrm{~s}^{-1}$ for spacing ratios $S / d 0.75$ and 1 , respectively.

From these results, it is obvious that at low impellers speed (up to $2.5 \mathrm{rps}$ ) the obtained $k_{l} a$ is close for all the tested spacing rations. For high impellers speed (higher than $2.5 \mathrm{rps}), k_{l} a$ is lower for the spacing ratio $S / d$ of 1 than that of 0.75 and 0.5 , and the difference becomes wider with increasing of rotation speed (see Figure 2) and the speed of 2.5 rps could be considered as a critical speed with respect to spacing impact.

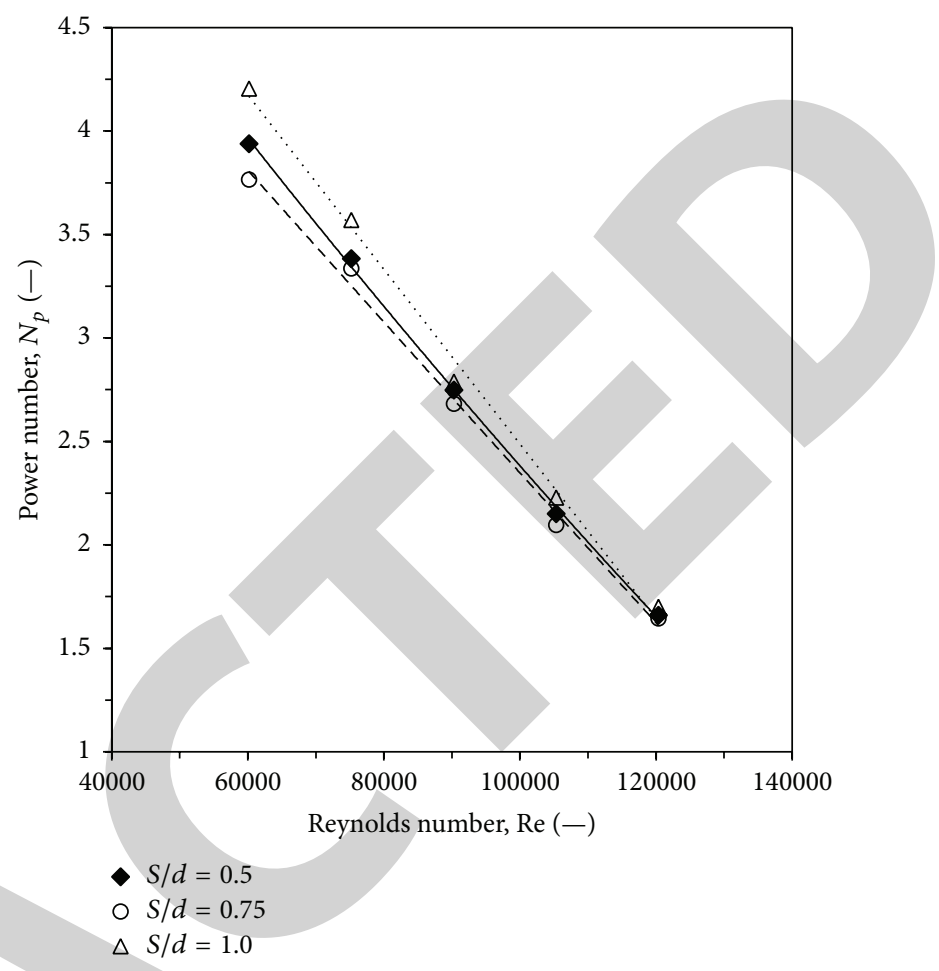

FIGURE 3: Spacing effect on the power consumption.

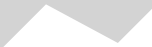

$k_{l} a$ was slightly lower at the spacing ratio $(S / d=1)$ when it is compared with the other positions $(S / d=0.75$ and 0.5 ) for higher rotation speeds $N>2.5 \mathrm{rps}$. This decreasing refers to the fact that with the lower position the interaction between the two impellers is weakened, since no other meaningful reasons can be developed with this replacement; in that way the spacing has an effect on the oxygen transferred.

\subsection{Effect of Spacing between Impellers on Power Consump-} tion. Figure 3 shows the power consumption in water bulk at the turbulent condition as a relation of the power number $N_{p}$ with Reynolds number Re for three investigated spacing ratios $S / d(0.5,0.75$, and 1.0$)$. A higher power was consumed with higher impellers rotation speed (lower power number). From Figure 3 it can be found that a relatively higher power was consumed (lower power number) for high impellers rotation speeds (higher Reynolds number) for the tested spacing ratios $S / d$, and this power consumption was almost similar for the different spacing ratios at high Reynolds numbers. The power consumption, in this case, is less relevant to the spacing between the two impellers at high Reynolds numbers (high rotation speeds). The power consumption showed the same behavior for elevating the rotation speed for all tested spacing rations, wherein higher rotation speed requires more power to be dissipated into water bulk to accomplish the objectives from impellers rotation.

3.3. Effect of Spacing between Impellers on Mixing Time. The tests of the spacing effect on the mixing time were carried 


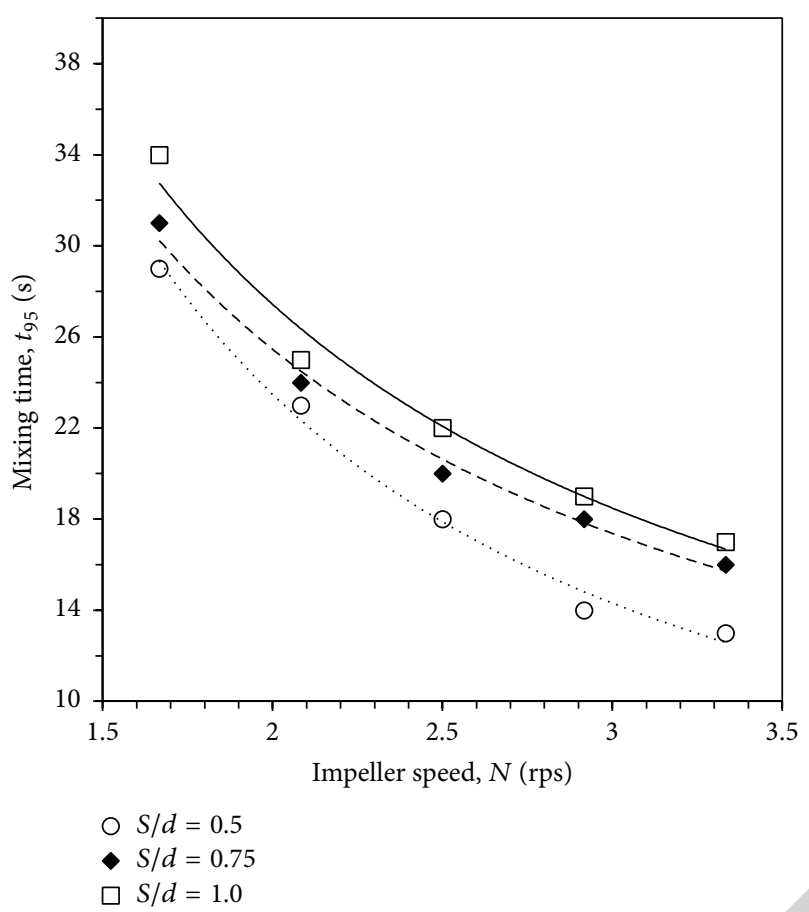

FIGURE 4: Relation between mixing time and spacing between impellers.

out in a gas-liquid (aerated) condition for three spacing ratios $S / d(0.5,0.75$, and 1.0$)$. The two impellers (IRSC and PBPU) were working together always with up-pumping condition. The mixing time was tested within the rotational speeds $N$ range of $1.67-3.33 \mathrm{rps}$.

The obtained spacing experimental results in Figure 4 illustrate that, with increasing spacing ratio, the mixing time increases for all tested impeller speeds (1.67-3.33 rps). For the spacing ratio $S / d=0.5$ (the lower impeller PBPU is positioned more inside in the tank), the mixing time shows a relative improvement compared with higher spacing ratios of $S / d=0.75$ and 1.0. This improvement begins slightly with the impellers speed equal to $2.5 \mathrm{rps}$ and becomes clearer at higher speeds. For the spacing ratio $S / d=1.0$, except for lower speed of $1.67 \mathrm{rps}$, the mixing time is slightly higher than that of the spacing ratio $S / d=0.75$ (see Figure 4 ). These results agree with Hsu and Huang [36]. These results demonstrate that mixing time increases with increasing spacing ratio and this comes from the fact that longer spacing causes weaker interactions for the axial flow between the impellers.

\section{Conclusions}

At the given water height, it was observed that $k_{l} a$ is relevant to the spacing ratios for all tested impellers rotation speed. The spacing between the impellers affects the oxygen mass transfer coefficient $k_{l} a$ in a way that the reliance of $k_{l} a$ on the spacing is conjugated with the interaction between the propeller and the upper impeller.

From the experimental runs for power consumption, it was found that the consumed power is related effectively with spacing variation, especially at lower rotation speeds. The power consumption is varied in agreement with mixing time for the different applied spacing positions. Mixing time shows an obvious dependence upon the spacing between the two impellers along the variation of rotation speed in the aeration conditions with different influence intensity.

From the experimental results, the rotation speed of $2.5 \mathrm{rps}$ is regarded as a critical rotational speed to show the effect of spacing ration on the oxygen mass transfer, power consumption, and mixing time. The impact of spacing ration starts to become clearer at this speed. The results show that, among the three tested spacing ratios $S / d(0.5,0.75$, and 1.0 ), the smaller one of 0.5 gave better values for the oxygen mass transfer, power consumption, and mixing time. Due to shorter spacing between the impellers a better axial flow interaction can be obtained.

\section{Nomenclature}

$a$ term in $k_{l} a$ : Interfacial area per unit volume in water bulk $\left(\mathrm{m}^{2} \mathrm{~m}^{-3}\right)$

$\mathrm{C}_{l}$ : Dissolved oxygen concentration in liquid $\left(\mathrm{mg} \mathrm{L}^{-1}\right)$

$C_{s}: \quad$ Concentration of dissolved oxygen at saturation $\left(\mathrm{mg} \mathrm{L}^{-1}\right)$

$C_{t}$ : $\quad$ Concentration of dissolved oxygen at time $t$ $\left(\mathrm{mg} \mathrm{L}^{-1}\right)$

$C_{o}$ : Initial concentration of dissolved oxygen at time $t=0\left(\mathrm{mg} \mathrm{L}^{-1}\right)$

D: $\quad$ Rotated cone turbine diameter $(\mathrm{m})$

$d: \quad$ Pitch blade propeller diameter $(\mathrm{m})$

$H$ : Water level in the vessel $(\mathrm{m})$

$k_{l} a: \quad \quad$ Volumetric oxygen mass transfer coefficient

(liquid bulk mass transfer zone) $\left(\mathrm{s}^{-1}\right)$

$k_{l} a_{20^{\circ} \mathrm{C}}$ : $\quad$ Volumetric oxygen mass transfer coefficient

at $10^{\circ} \mathrm{C}$ (liquid bulk mass transfer zone) $\left(\mathrm{s}^{-1}\right)$

$k_{l} a_{\theta}: \quad$ Volumetric oxygen mass transfer coefficient at $\theta^{\circ} \mathrm{C}$ (liquid bulk mass transfer zone) $\left(\mathrm{s}^{-1}\right)$

$N: \quad$ Rotation speed $\left(\mathrm{s}^{-1}\right)$

$N_{p}: \quad$ Power number $\left(P / \rho N^{3} D^{5}\right)$

$P: \quad$ Power consumed (watt)

Re: $\quad$ Reynolds number $\left(\rho N D^{2} / \mu\right)$

$S: \quad$ Spacing between two impellers $(\mathrm{m})$

$t: \quad$ Time $(\mathrm{s})$

$t_{95}: \quad$ Mixing time (s)

$T_{o}$ : $\quad$ Torque measured with filled vessel $(\mathrm{N} \mathrm{m})$

$T_{o e}: \quad \quad \quad$ Torque measured with empty vessel $(\mathrm{N} \mathrm{m})$

$T: \quad \quad$ Vessel diameter $(\mathrm{m})$

$W: \quad$ Turbine blade width (m).

Greek Symbols

$\rho:$ Water density $\left(\mathrm{kg} \mathrm{m}^{-3}\right)$

$\tau$ : Probe time constant (s)

$\mu$ : Water dynamic viscosity $\left(\mathrm{kg} \mathrm{m}^{-1} \mathrm{~s}^{-1}\right)$

$\theta$ : Temperature $\left({ }^{\circ} \mathrm{C}\right)$. 
Impellers Types Abbreviations

IBRC: Inverted pitched rotated cone (developed particularly for surface aeration), up-pumping

PBPU: Pitch blade propeller, up-pumping.

\section{Conflict of Interests}

The author declares that there is no conflict of interests regarding the publication of this paper.

\section{Acknowledgments}

The author wishes to express his gratitude to Dr. Catherine Xuereb for sharing her knowledge and experience. The important contribution of Dr. Martine Poux is gratefully acknowledged. The contributions of the INP-LGC (Toulouse, France) and Biotrade-Toulouse are also gratefully acknowledged.

\section{References}

[1] A. W. Patwardhan and J. B. Joshi, "Design of gas-inducing reactors," Industrial \& Engineering Chemistry Research, vol. 38, no. 1, pp. 49-80, 1999.

[2] J. Gimbun, C. D. Rielly, and Z. K. Nagy, "Modelling of mass transfer in gas-liquid stirred tanks agitated by Rushton turbine and CD-6 impeller: a scale-up study," Chemical Engineering Research \& Design, vol. 87, no. 4, pp. 437-451, 2009.

[3] G. Montante, F. Laurenzi, A. Paglianti, and F. Magelli, “Twophase flow and bubble size distribution in air-sparged and surface-aerated vessels stirred by a dual impeller," Industrial \& Engineering Chemistry Research, vol. 49, no. 6, pp. 2613-2623, 2010.

[4] K. Yapici, B. Karasozen, M. Schäfer, and Y. Uludag, "Numerical investigation of the effect of the Rushton type turbine design factors on agitated tank flow characteristics," Chemical Engineering and Processing: Process Intensification, vol. 47, no. 8, pp. 1346-1355, 2008.

[5] J. M. T. Vasconcelos, S. C. P. Orvalho, A. M. A. F. Rodrigues, and S. S. Alves, "Effect of blade shape on the performance of six-bladed disk turbine impellers," Industrial \& Engineering Chemistry Research, vol. 39, no. 1, pp. 203-213, 2000.

[6] S. D. Shewale and A. B. Pandit, "Studies in multiple impeller agitated gas-liquid contactors," Chemical Engineering Science, vol. 61, no. 2, pp. 489-504, 2006.

[7] B. Azzopardi, D. Zhao, Y. Yan, H. Morvan, R. Mudde, and S. Lo, Hydrodynamics of Gas-Liquid Reactors: Normal Operation and Upset Conditions, John Wiley \& Sons, New York, NY, USA, 2011.

[8] Y. Bao, J. Yang, L. Chen, and Z. Gao, "Influence of the top impeller diameter on the gas dispersion in a sparged multiimpeller stirred tank," Industrial \& Engineering Chemistry Research, vol. 51, no. 38, pp. 12411-12420, 2012.

[9] H. M. Issa, M. Poux, and C. Xuereb, "Surface aeration for water treatment agitated tank mixing time, power consumption and hydrodynamics," in Proceedings of the 14th European Conference on Mixing, pp. 169-174, Warsaw, Poland, September 2012.

[10] T. Adachi, "Oxygen transfer and power consumption in an aeration system using mist and circulation flow generated by a rotating cone," Chemical Engineering Science, vol. 126, pp. 625$632,2015$.

[11] V. Hudcova, V. Machon, and A. Nienow, "Gas-liquid dispersion with dual Rushton impellers," Biotechnology and Bioengineering, vol. 34, no. 5, pp. 617-628, 1989.

[12] D. Chapple, S. M. Kresta, A. Wall, and A. Afacan, "The effect of impeller and tank geometry on power number for a pitched blade turbine," Chemical Engineering Research and Design, vol. 80, no. 4, pp. 364-372, 2002.

[13] A. Karimi, F. Golbabaei, M. R. Mehrnia et al., "Investigation of gas hold up and power consumption in a stirred tank bioreactor using single and dual impeller configurations," International Journal of Occupational Hygiene, vol. 5, no. 3, pp. 109-116, 2013.

[14] M. O. Albaek, K. V. Gernaey, and S. M. Stocks, "Gassed and ungassed power draw in a pilot scale 550 litre fermentor retrofitted with up-pumping hydrofoil B2 impellers in media of different viscosity and with very high power draw," Chemical Engineering Science, vol. 63, no. 24, pp. 5813-5820, 2008.

[15] J. Markopoulos, E. Babalona, and E. Tsiliopoulou, "Power consumption in agitated vessels with dual Rushton turbines: baffle length and impeller spacing effects," Chemical Engineering \& Technology, vol. 27, no. 11, pp. 1212-1215, 2004.

[16] L. Broniarz-Press, S. Woziwodzki, and M. Ochowiak, "Power consumption for non-aerated $\mathrm{Na}-\mathrm{CMC}$ solutions in multiple bioreactors agitated," in Proceedings of the European Congress of Chemical Engineering (ECCE-6 '07), pp. 1-8, Copenhagen, Denmark, September 2007.

[17] D. Hari-Prajitno, V. P. Mishra, K. Takenaka, W. Bujalski, A. W. Nienow, and J. McKemmie, "Gas-liquid mixing studies with multiple up- and down-pumping hydrofoil impellers: power characteristics and mixing time," Canadian Journal of Chemical Engineering, vol. 76, no. 6, pp. 1056-1068, 1998.

[18] S. M. Mahmoudi and M. Yianneskis, "The variation of flow pattern and mixing time with impeller spacing in stirred vessels with two Rushton impellers," in Fluid Mechanics of Mixing, R. King, Ed., vol. 10 of Fluid Mechanics and Its Applications, pp. 11-18, Springer, 1992.

[19] S. Xueming, L. Xiaoling, and L. Yulin, "Experimental study of influence of the impeller spacing on flow behaviour of doubleimpeller stirred tank," The Canadian Journal of Chemical Engineering, vol. 81, no. 6, pp. 1239-1245, 2003.

[20] G. Montante and F. Magelli, "Liquid homogenization characteristics in vessels stirred with multiple Rushton turbines mounted at different spacings: CFD study and comparison with experimental data," Chemical Engineering Research and Design, vol. 82, no. 9, pp. 1179-1187, 2004.

[21] F. Magelli, G. Montante, D. Pinelli, and A. Paglianti, "Mixing time in high aspect ratio vessels stirred with multiple impellers," Chemical Engineering Science, vol. 101, pp. 712-720, 2013.

[22] S. T. You, A. A. A. Raman, R. S. S. R. E. Shah, and M. I. M. Nor, "Multiple-impeller stirred vessel studies," Reviews in Chemical Engineering, vol. 30, no. 3, pp. 323-336, 2014.

[23] P. C. Lines, "Gas-liquid mass transfer using surface-aeration in stirred vessels, with dual impellers," Chemical Engineering Research and Design, vol. 78, no. 3, pp. 342-347, 2000.

[24] M. Bouaifi, G. Hebrard, D. Bastoul, and M. Roustan, "A comparative study of gas hold-up, bubble size, interfacial area and mass transfer coefficients in stirred gas-liquid reactors and bubble columns," Chemical Engineering and Processing, vol. 40, no. 2, pp. 97-111, 2001.

[25] J.-C. Gabelle, F. Augier, A. Carvalho, R. Rousset, and J. Morchain, "Effect of tank size on kLa and mixing time in aerated 
stirred reactors with non-newtonian fluids," The Canadian Journal of Chemical Engineering, vol. 89, no. 5, pp. 1139-1153, 2011.

[26] M. Xie, J. Xia, Z. Zhou, J. Chu, Y. Zhuang, and S. Zhang, "Flow pattern, mixing, gas hold-up and mass transfer coefficient of triple-impeller configurations in stirred tank bioreactors," Industrial \& Engineering Chemistry Research, vol. 53, no. 14, pp. 5941-5953, 2014.

[27] T. Moucha, V. Linek, and E. Prokopová, “Gas hold-up, mixing time and gas-liquid volumetric mass transfer coefficient of various multiple-impeller configurations: Rushton turbine, pitched blade and techmix impeller and their combinations," Chemical Engineering Science, vol. 58, no. 9, pp. 1839-1846, 2003.

[28] P. Mavros, "Flow visualization in stirred vessels: a review of experimental techniques," Chemical Engineering Research and Design, vol. 79, no. 2, pp. 113-127, 2001.

[29] J. C. Merchuk, S. Yona, M. H. Siegel, and A. B. Zvi, "On the first-order approximation to the response of dissolved oxygen electrodes for dynamic KLa estimation," Biotechnology and Bioengineering, vol. 35, no. 11, pp. 1161-1163, 1990.

[30] J. A. Mueller, W. C. Boyle, and E. N. Lightfoot, "Effect of the response time of a dissolved oxygen probe on the oxygen uptake rate," Applied Microbiology, vol. 15, no. 3, pp. 674-676, 1967.

[31] M. S. Puthli, V. K. Rathod, and A. B. Pandit, "Gas-liquid mass transfer studies with triple impeller system on a laboratory scale bioreactor," Biochemical Engineering Journal, vol. 23, no. 1, pp. 25-30, 2005.

[32] S. J. Arjunwadkar, K. Sarvanan, P. R. Kulkarni, and A. B. Pandit, "Gas-liquid mass transfer in dual impeller bioreactor," Biochemical Engineering Journal, vol. 1, no. 2, pp. 99-106, 1998.

[33] J.-M. Chern and S.-P. Yang, "Oxygen transfer rate in a coarsebubble diffused aeration system," Industrial \& Engineering Chemistry Research, vol. 42, no. 25, pp. 6653-6660, 2003.

[34] R. Sardeing, M. Poux, S. Melen, P. Avrillier, and C. Xuereb, "Aeration of large size tanks by a surface agitator," Chemical Engineering \& Technology, vol. 28, no. 5, pp. 587-595, 2005.

[35] S. Capela, S. Gillot, and A. Héduit, "Comparison of oxygentransfer measurement methods under process conditions," Water Environment Research, vol. 76, no. 2, pp. 183-188, 2004.

[36] Y.-C. Hsu and K.-F. Huang, "Effects of geometrical factors on liquid mixing in a gas-induced agitated tank," Journal of Chemical Technology and Biotechnology, vol. 68, no. 2, pp. 222-

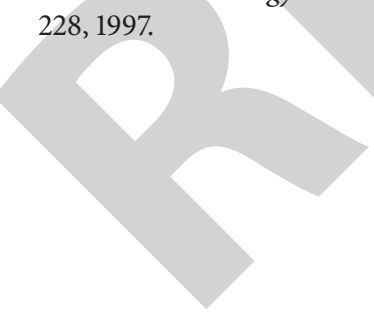

